\title{
Virstatin-conjugated gold nanoparticle with enhanced antimicrobial activity against Vibrio cholerae El Tor biotype
}

\author{
Swapan Kumar Jana, ${ }^{1}$ Arin Gucchait, ${ }^{2}$ Susmita Paul, ${ }^{3}$ Tultul Saha, ${ }^{4}$ \\ Somobrata Acharya, ${ }^{3}$ Kazi Mirajul Hoque, ${ }^{4}$ Anup Kumar Misra, ${ }^{2}$ Barun \\ K. Chatterjee, ${ }^{5}$ Tanaya Chatterjee ${ }^{1}$ and Pinak Chakrabarti ${ }^{1, *}$ \\ ${ }^{1}$ Department of Biochemistry, Bose Institute, P1/12 CIT Scheme VIIM, Kolkata 700054, \\ India \\ ${ }^{2}$ Divison of Molecular Medicine, Bose Institute, P1/12 CIT Scheme VIIM, Kolkata 700054, \\ India \\ ${ }^{3}$ School of Applied \& Interdisciplinary Sciences, Indian Association for the Cultivation of \\ Science, Jadavpur, Kolkata 700032, India \\ ${ }^{4}$ Division of Molecular Pathophysiology, National Institute of Cholera \& Enteric Diseases, \\ P-33 CIT Road, Scheme XM, Beliaghata, Kolkata 700010, India \\ ${ }^{5}$ Department of Physics, Bose Institute, 93/1 A.P.C. Road, Kolkata 700009, India
}

*Author for correspondence: pinak@jcbose.ac.in

\section{Supplementary Material}



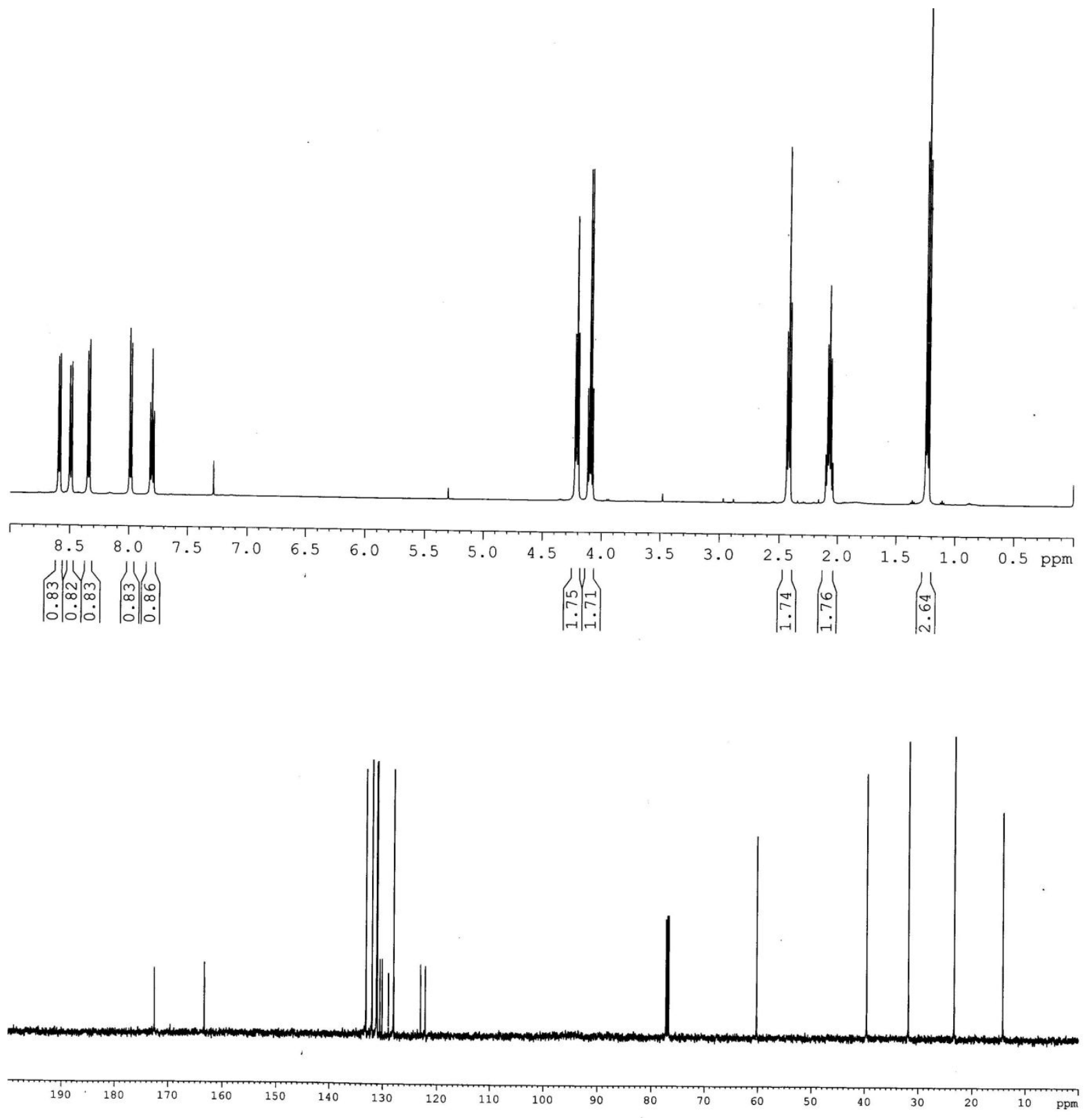


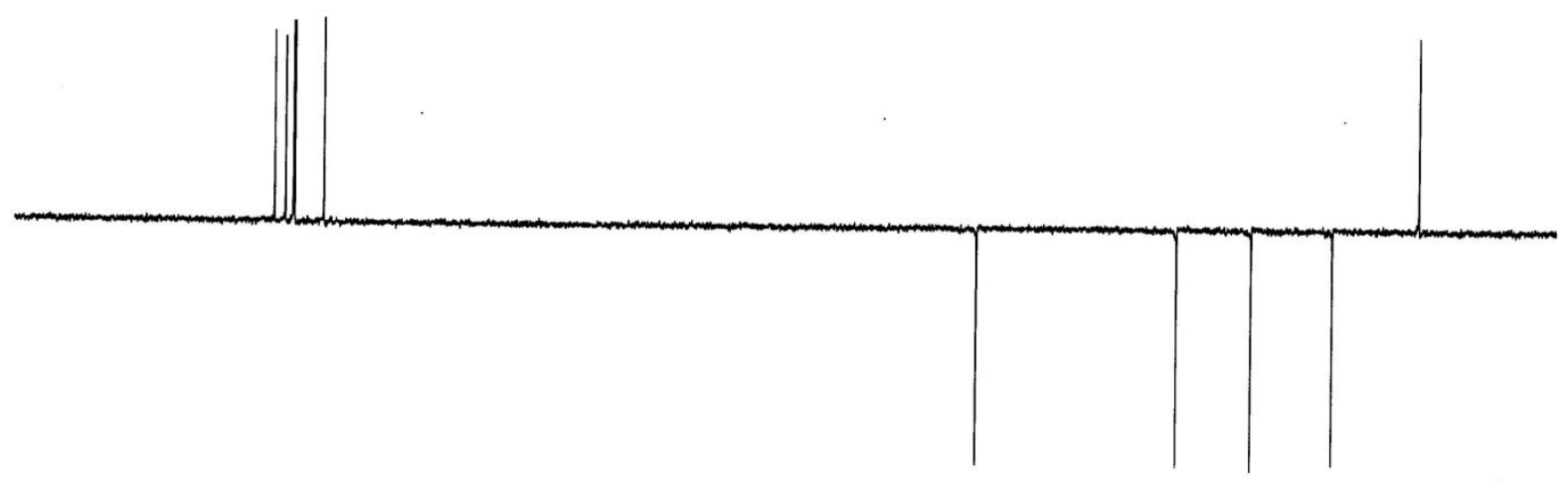

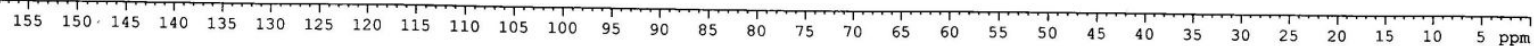

${ }^{1} \mathrm{H},{ }^{13} \mathrm{C}$ and DEPT 135 NMR spectra of ethyl 4-[6-bromo-1,3-dioxo-1 $H$ benzo[de]isoquinolin-2(3H)-yl]butanoate (2) $\left(500 \mathrm{MHz}, \mathrm{CDCl}_{3}\right)$.
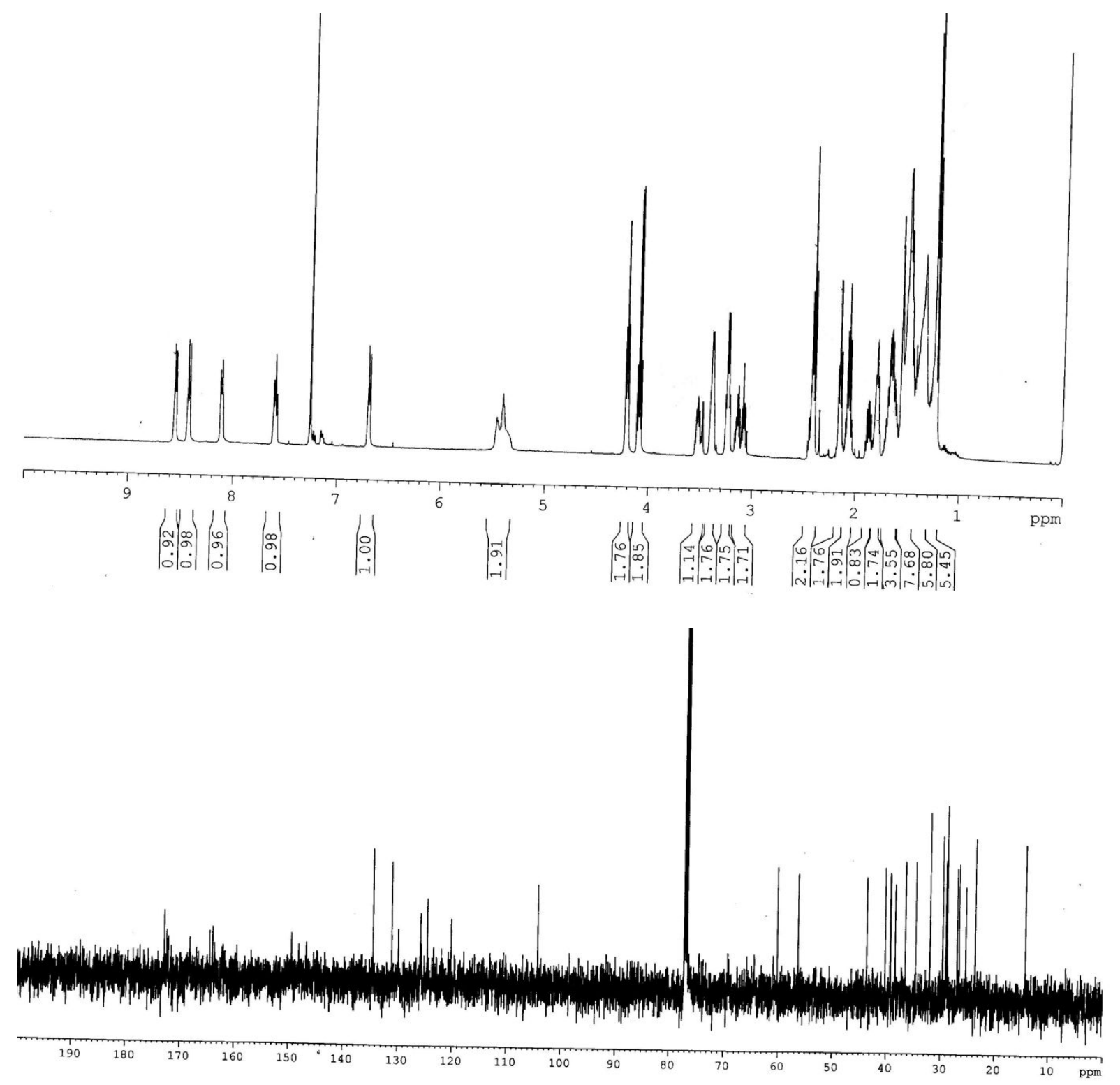


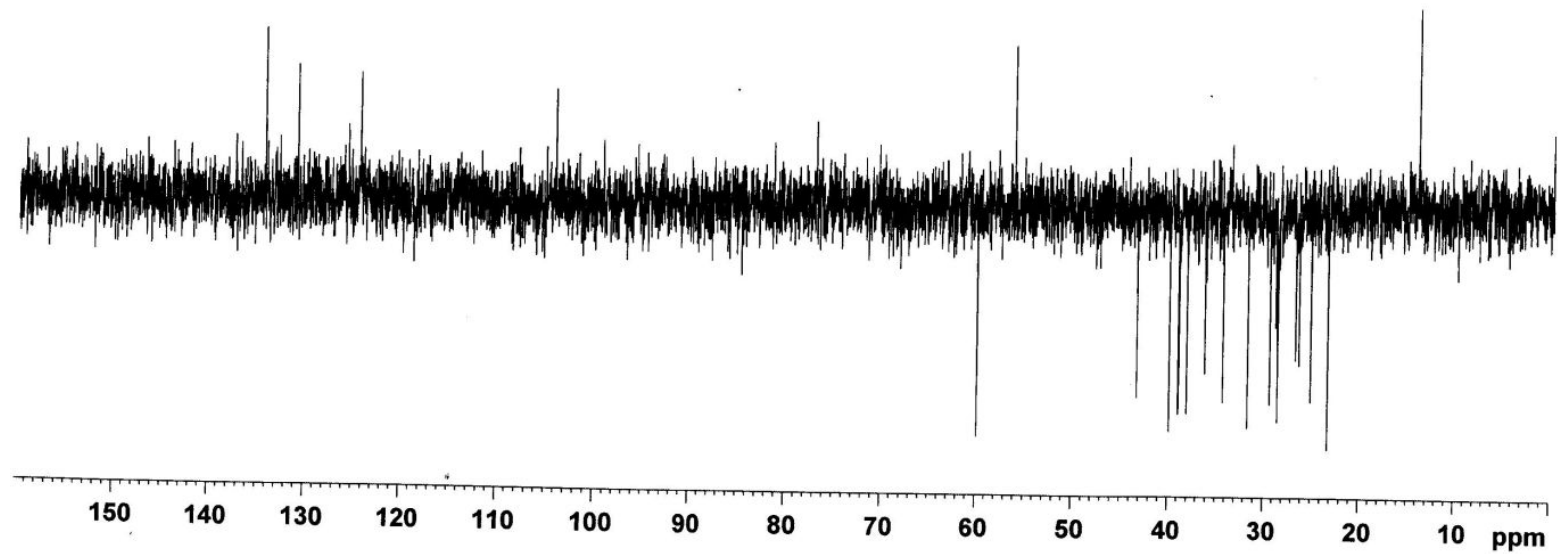

${ }^{1} \mathrm{H},{ }^{13} \mathrm{C}$ and DEPT 135 NMR spectra of ethyl 4-(6-(8-(5-(1,2-dithiolan-3yl)pentanamido)octylamino)-1,3-dioxo-1H-benzo[de]isoquinolin-2(3H)-yl)butanoate (3) (500 MHz, $\left.\mathrm{CDCl}_{3}\right)$.

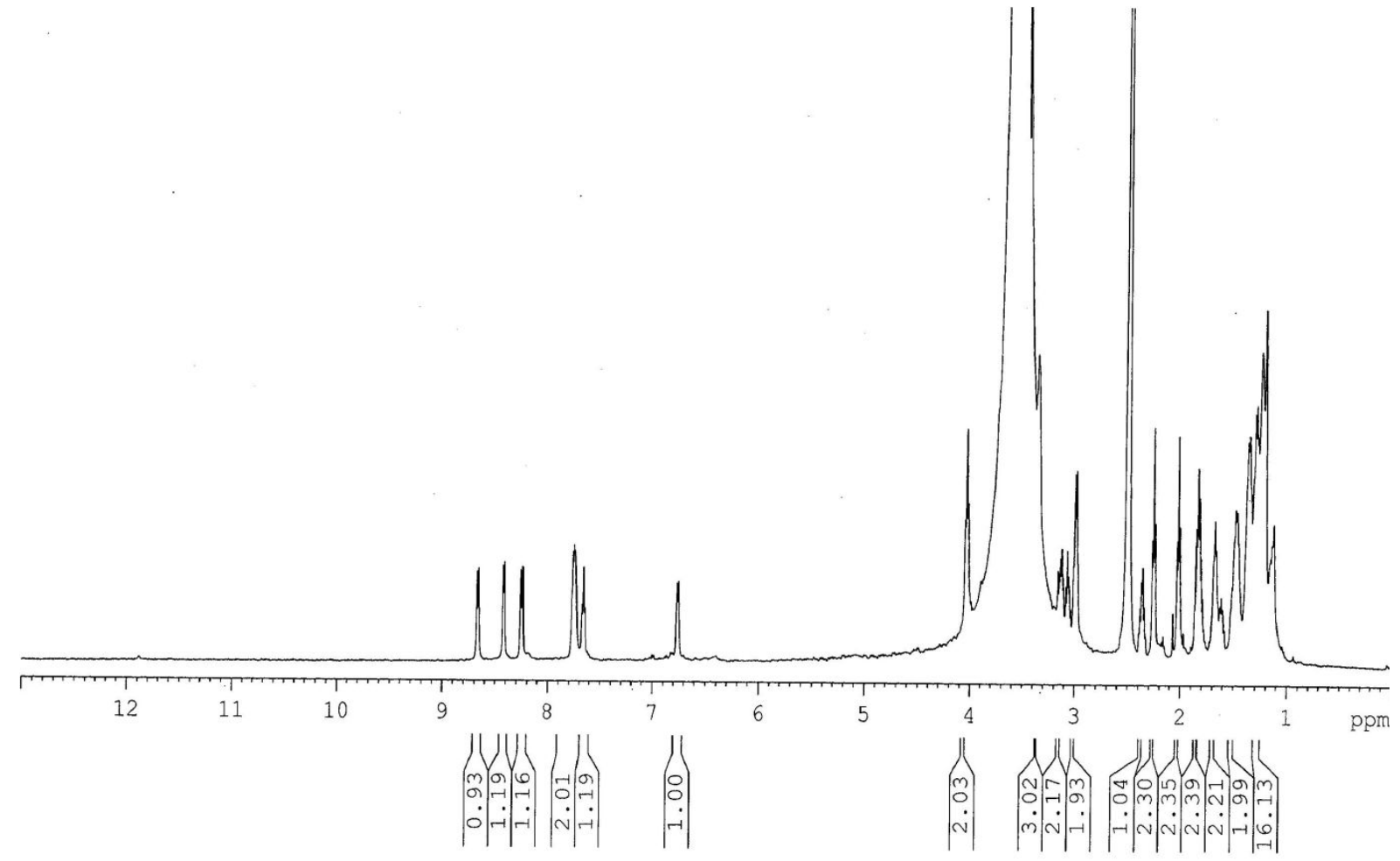




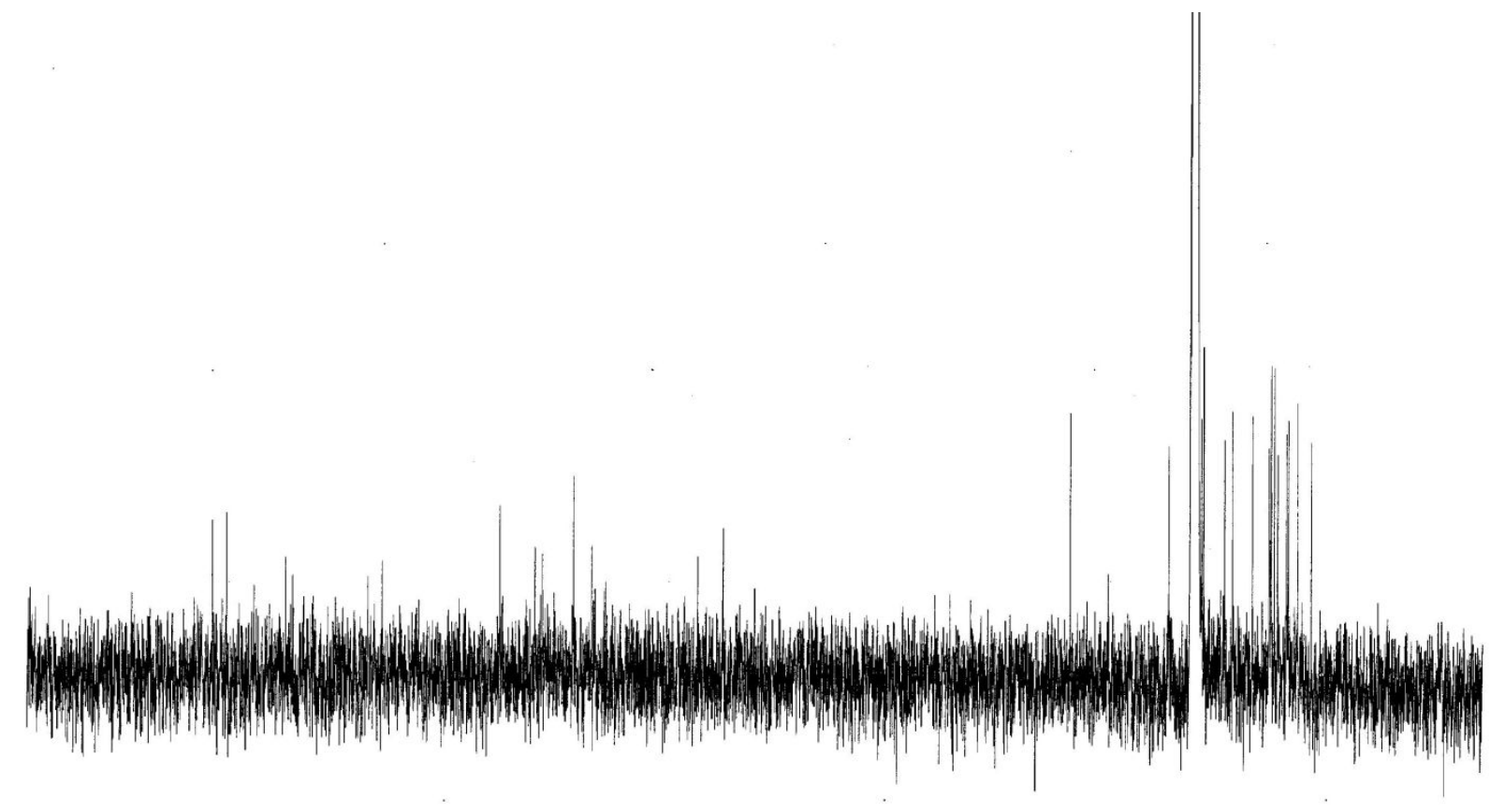

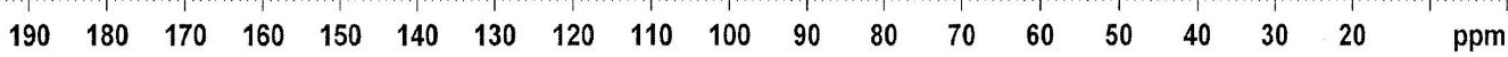

${ }^{1} \mathrm{H}$ and ${ }^{13} \mathrm{C}$ NMR spectra of 4-(6-(8-(5-(1,2-dithiolan-3-yl)pentanamido)octylamino)-1,3dioxo-1H-benzo[de]isoquinolin-2(3H)-yl)butanoic acid (4) (500 $\left.\mathrm{MHz}, \mathrm{CDCl}_{3}\right)$.

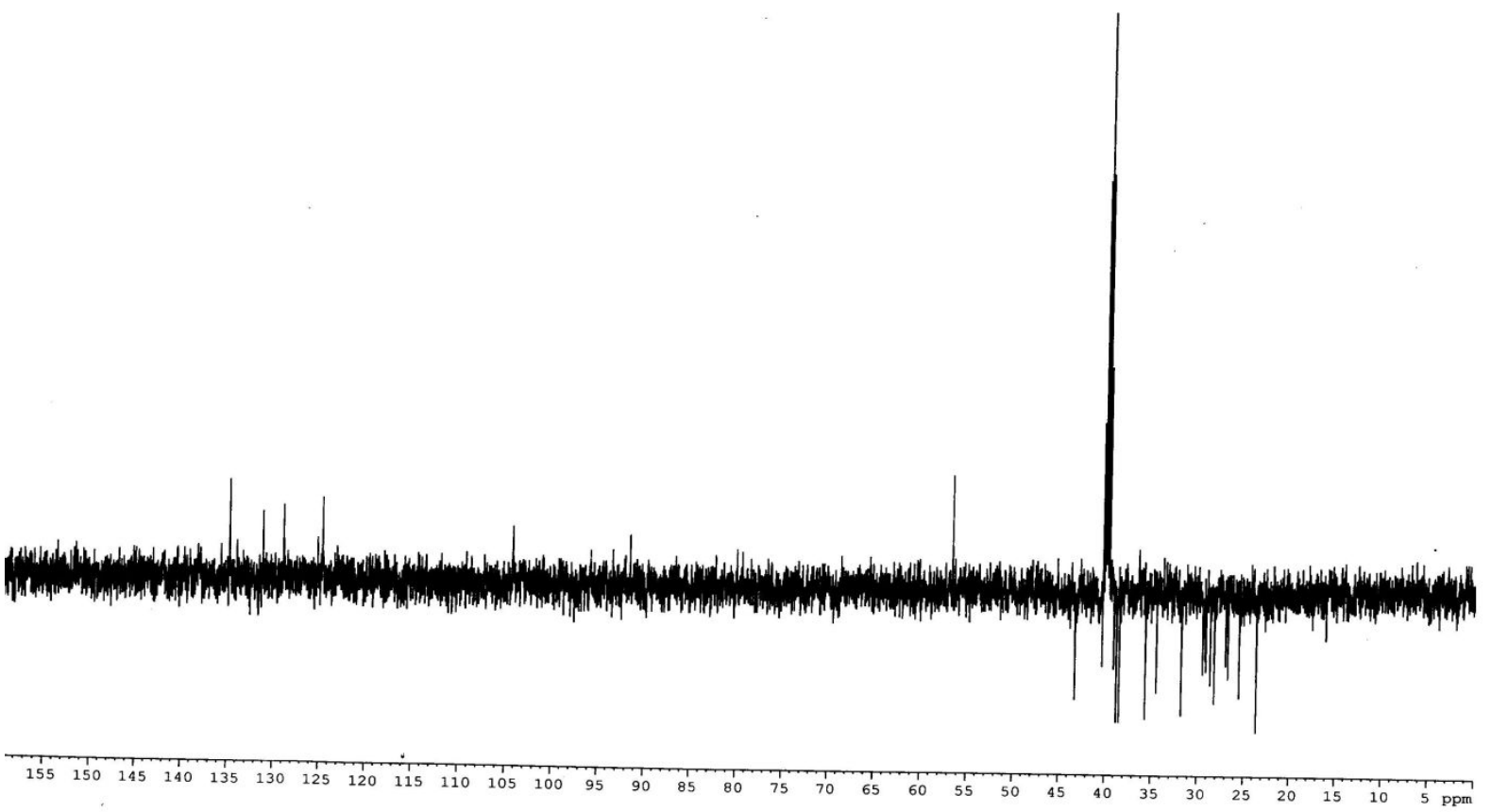

${ }^{13}$ C DEPT 135 NMR spectrum of 4-(6-(8-(5-(1,2-dithiolan-3-

yl)pentanamido)octylamino)-1,3-dioxo-1H-benzo[de]isoquinolin-2(3H)-yl)butanoic acid (4) (500 MHz, $\left.\mathrm{CDCl}_{3}\right)$. 


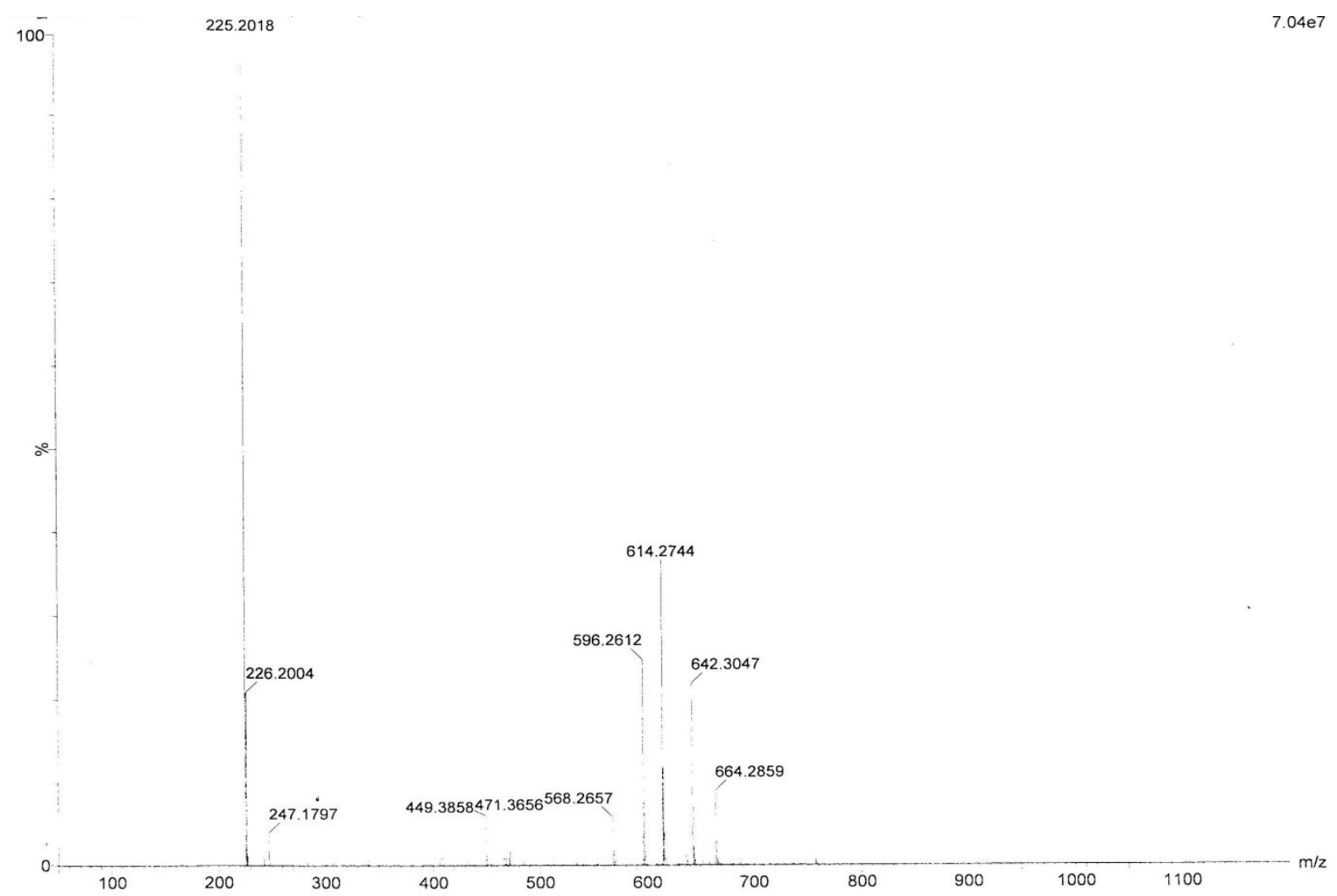

Mass spectrum of 4-(6-(8-(5-(1,2-dithiolan-3-yl)pentanamido)octylamino)-1,3-dioxo-1Hbenzo[de]isoquinolin-2(3H)-yl)butanoic acid (4).

Figure S1. NMR and Mass spectral data of various compounds synthesized. 


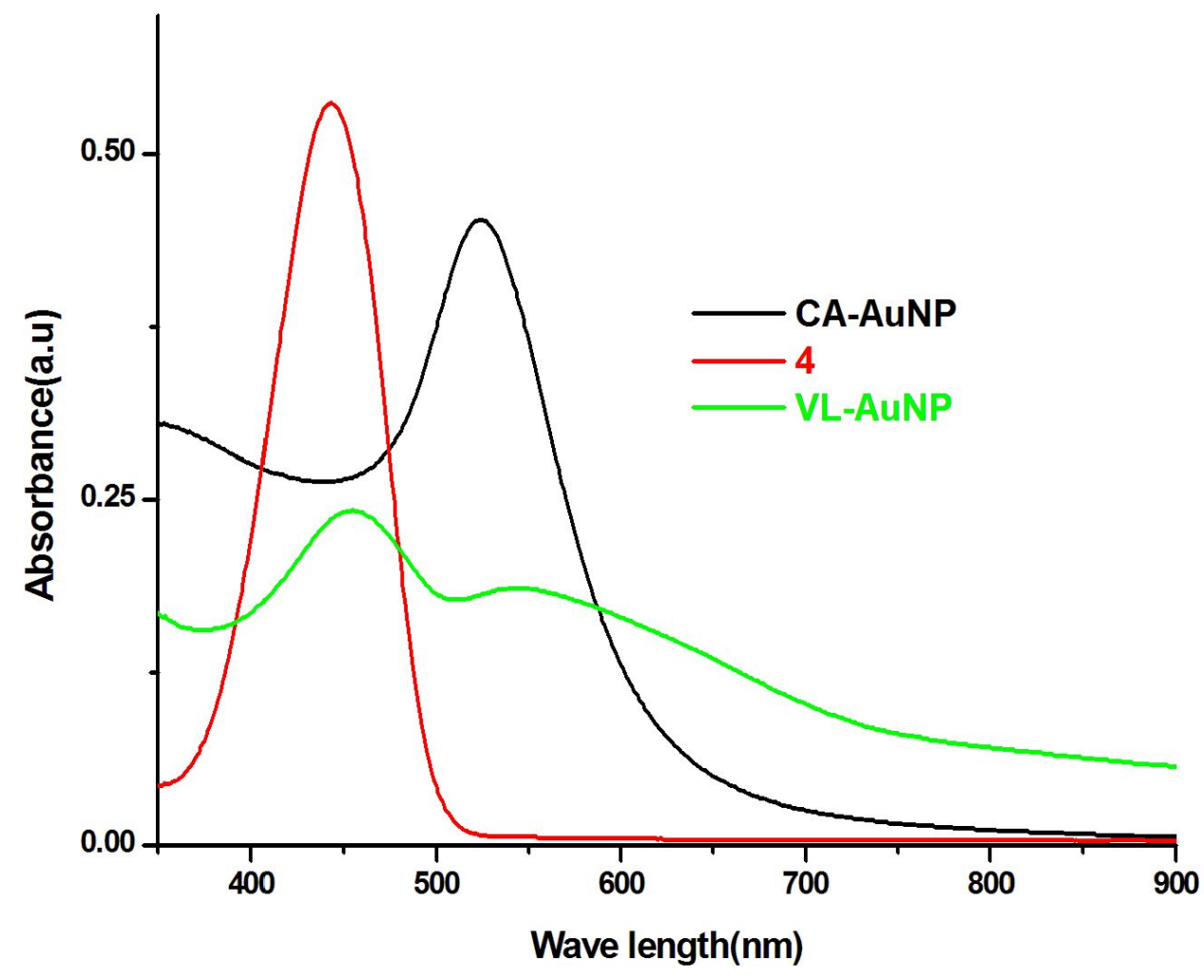

Figure S2. UV-vis spectra of citrate stabilized AuNPs (CA-AuNPs), 4 and 4 conjugated to AuNPs (VL-AuNPs). 


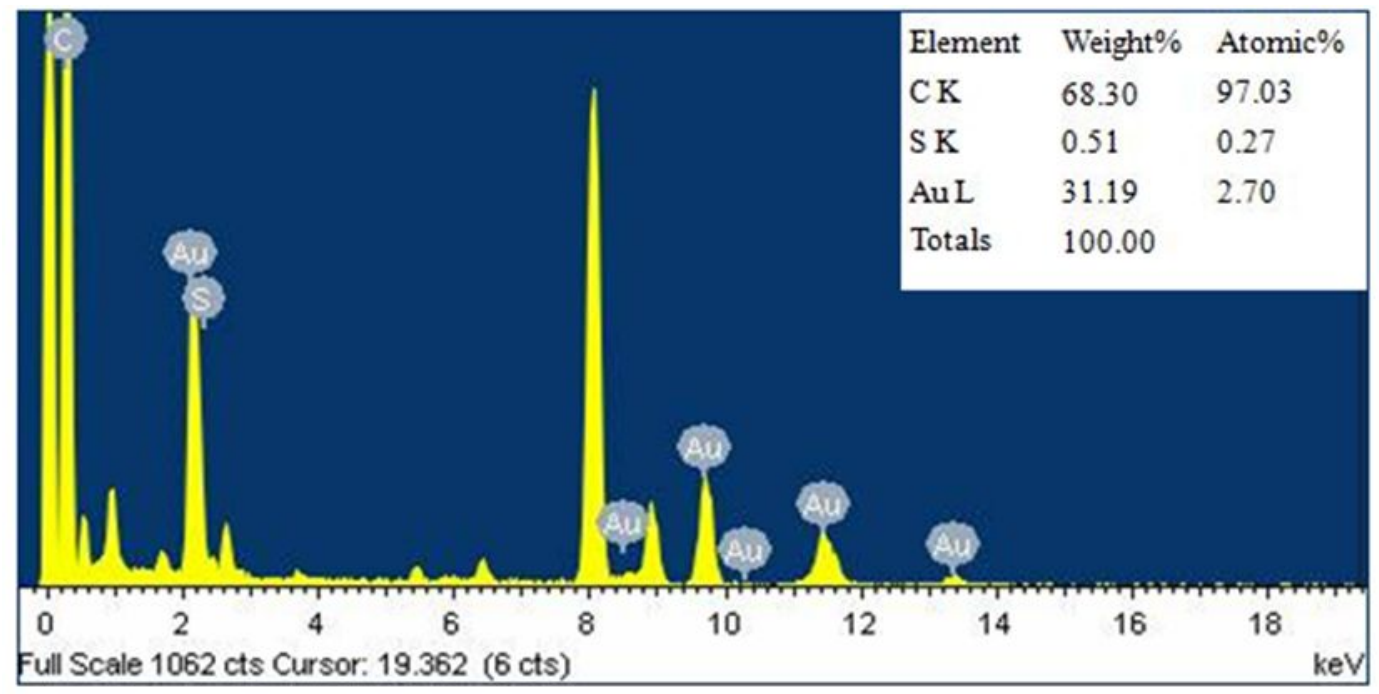

Figure S3. Energy dispersive X-ray (EDX) spectrum of VL-AuNPs. 


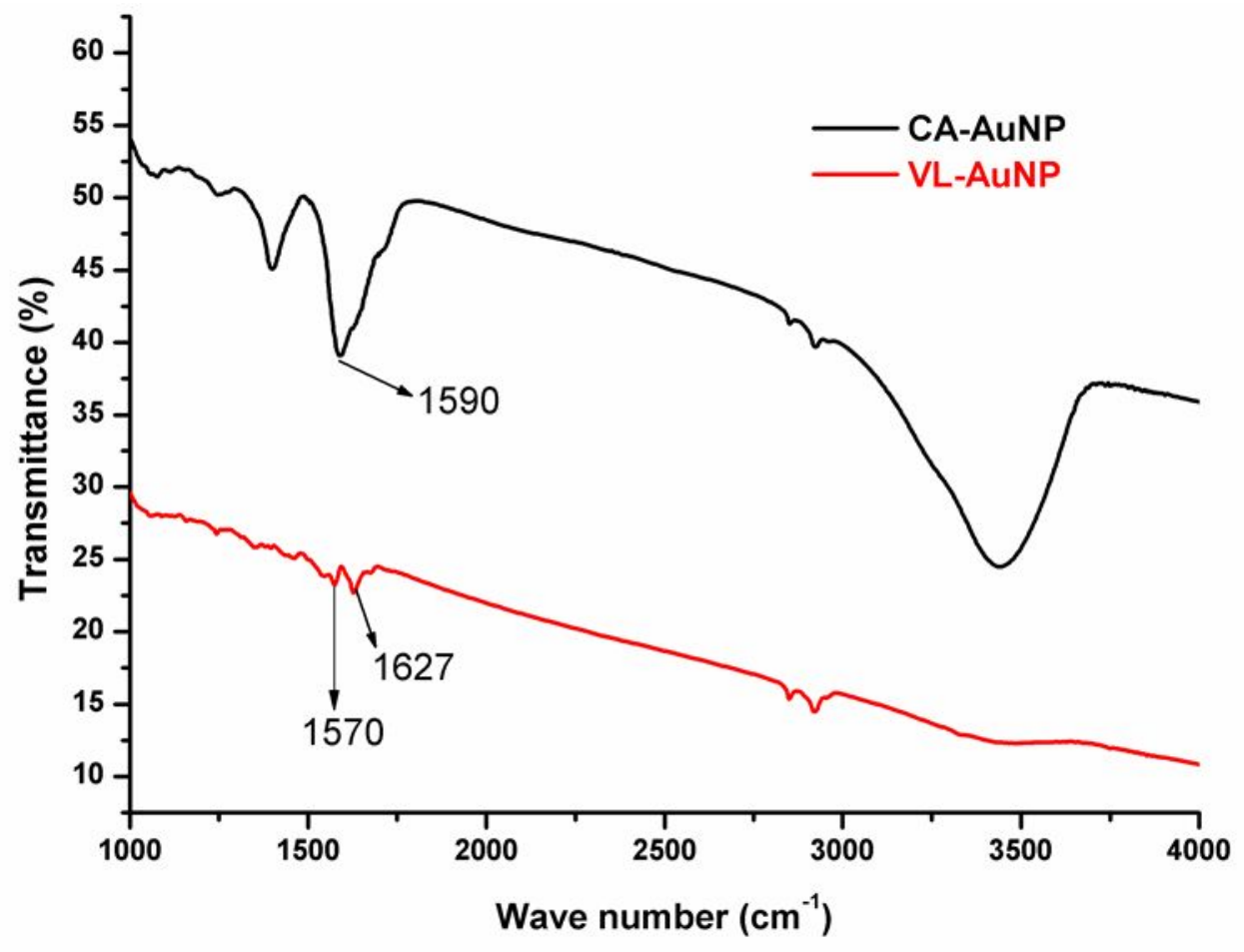

Figure S4. Transmission IR spectra of CA-AuNPs and VL-AuNPs. IR peak at $1590 \mathrm{~cm}^{-1}$ indicates the presence of $-\mathrm{COOH}$ group in CA-AuNPs and the peak at 1570 and $1627 \mathrm{~cm}^{-1}$ indicates the presence of $-\mathrm{COOH}$ and $-\mathrm{CONH}$ group, respectively in VL-AuNPs.

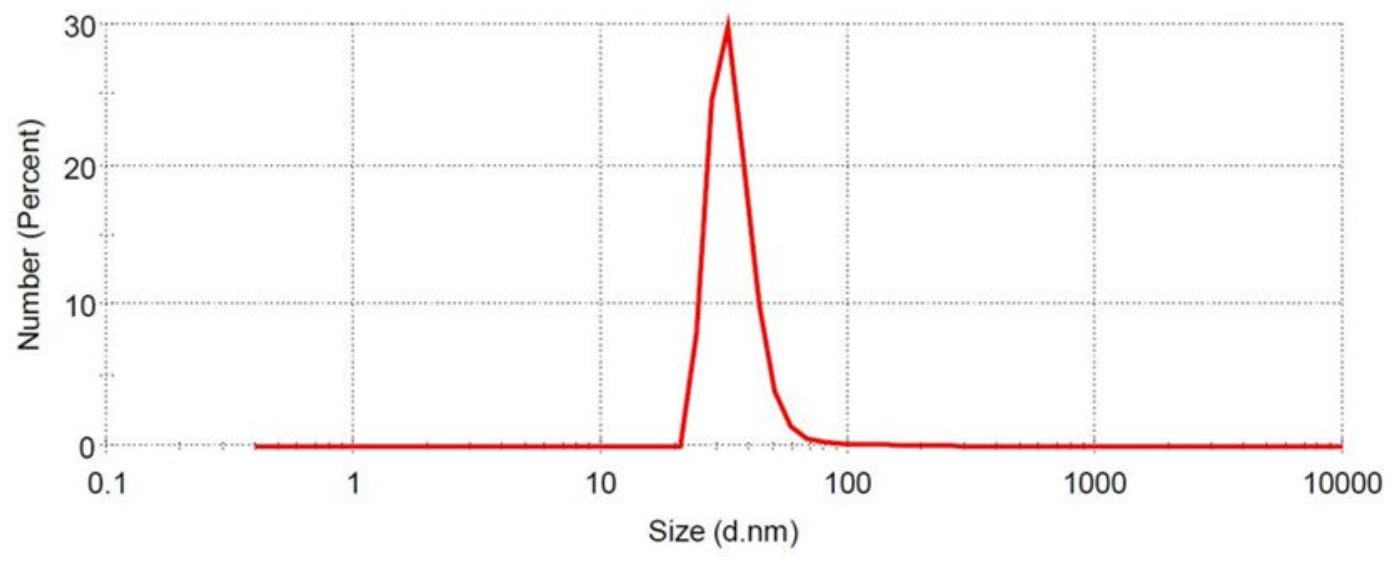

Figure S5. DLS measurement of hydrodynamic size distribution of VL-AuNPs. 


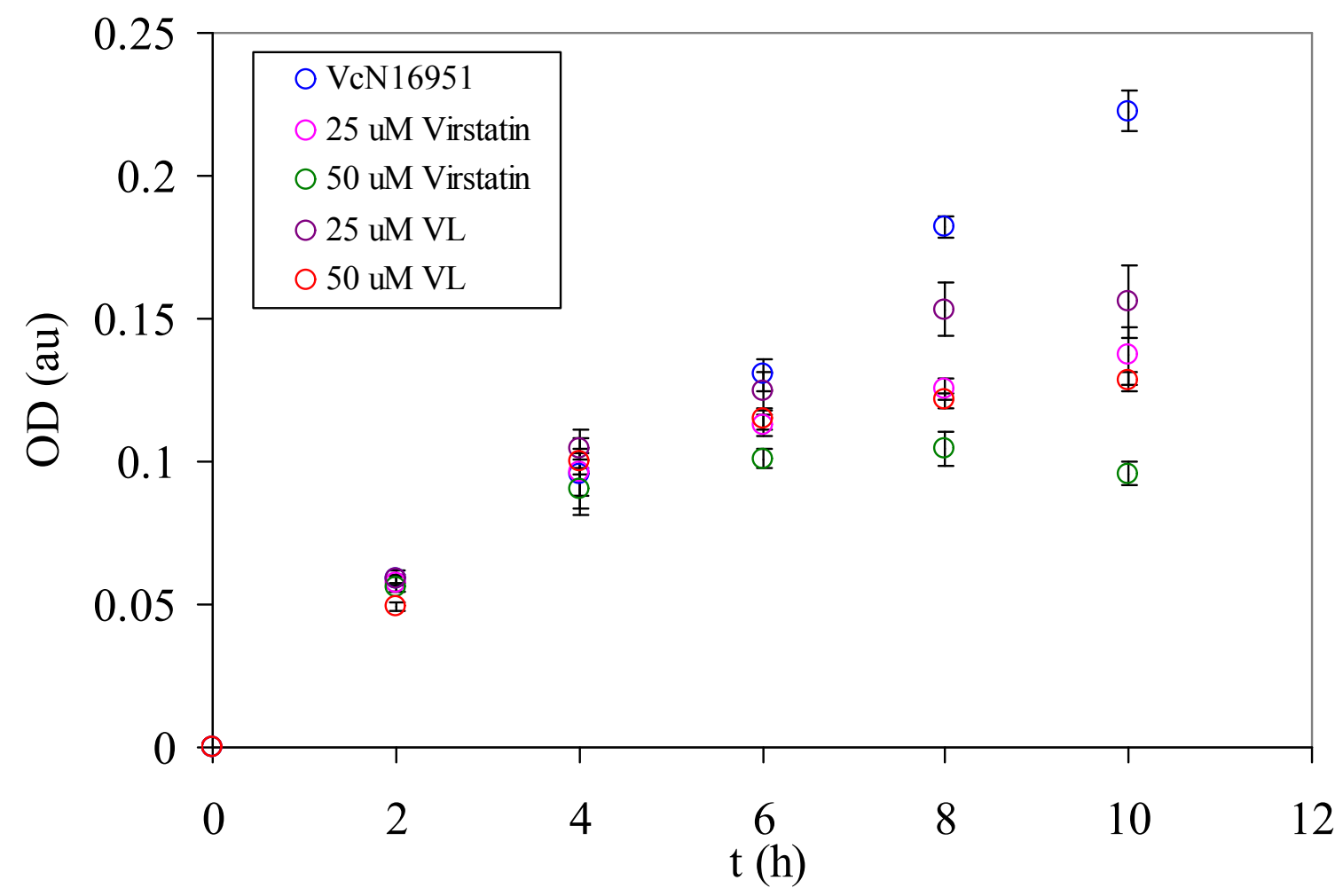

Figure S6. Comparative growth kinetics of $V c$ N16961 with virstatin and lipoic acid appended virstatin (VL), at two different concentrations (at $\mu \mathrm{M}$ range). Data are averaged from three sets of experiments. 


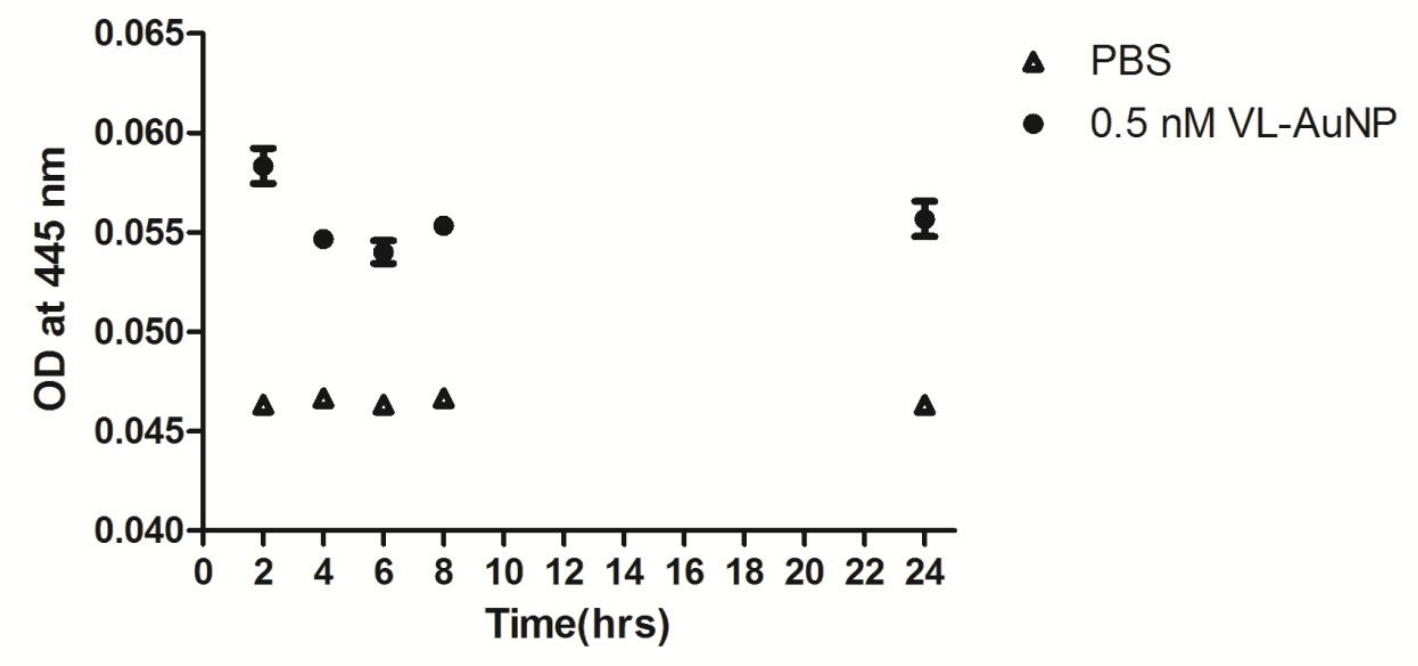

Figure S7. Profile of the release of VL from VL-AuNP at different time points in PBS $(\mathrm{pH}=7.4)$. The results are represented as mean $\pm \mathrm{SD}(\mathrm{n}=3)$.
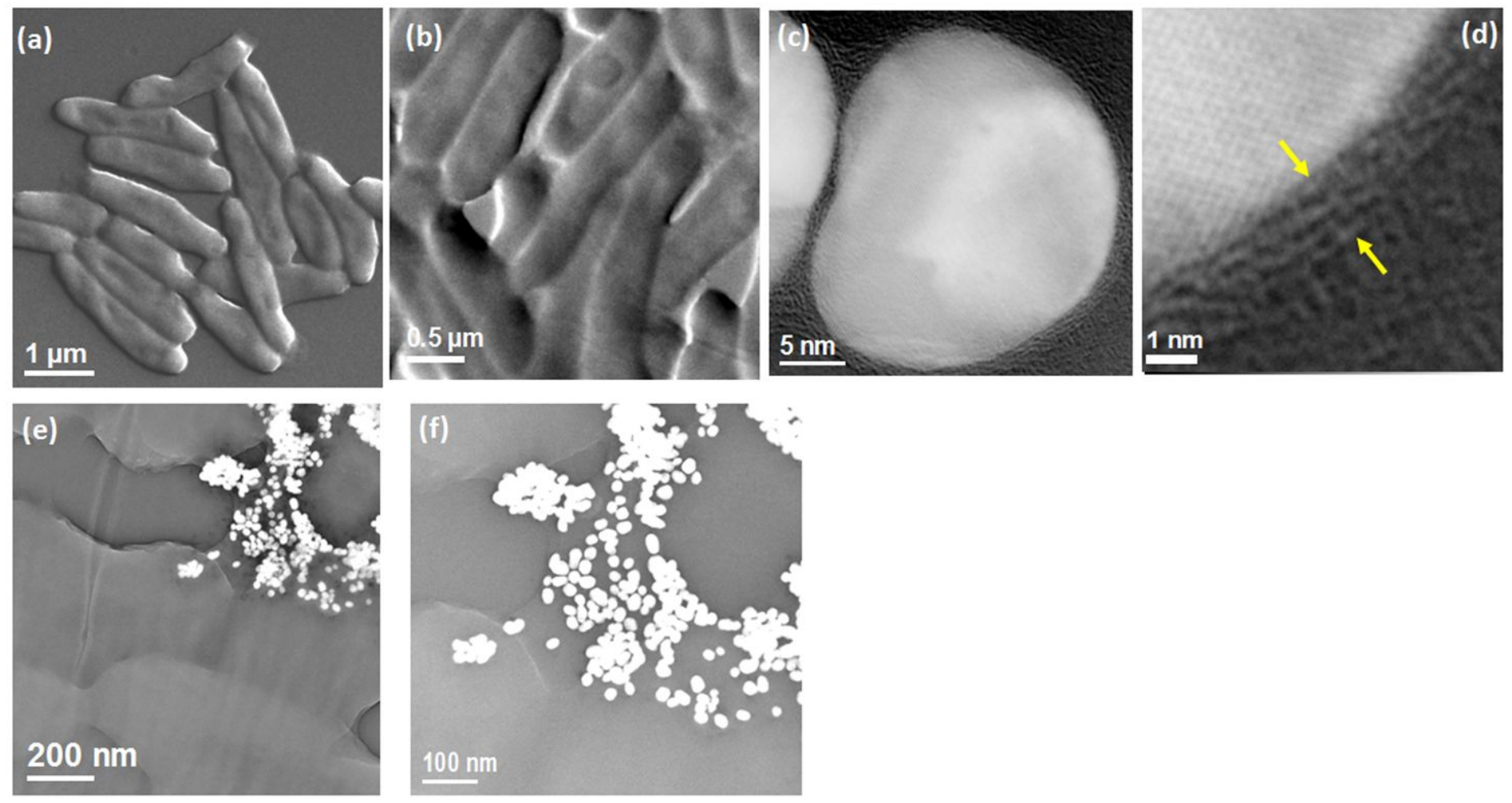

Figure S8. TEM images of (a,b) Gram-negative $V c$ N16961 at different resolution; (c, d) VLAuNPs at different resolution; and (e, f) VL-AuNPs treated $V c$ N16961. The virstatin coating is marked by arrows in (d). 


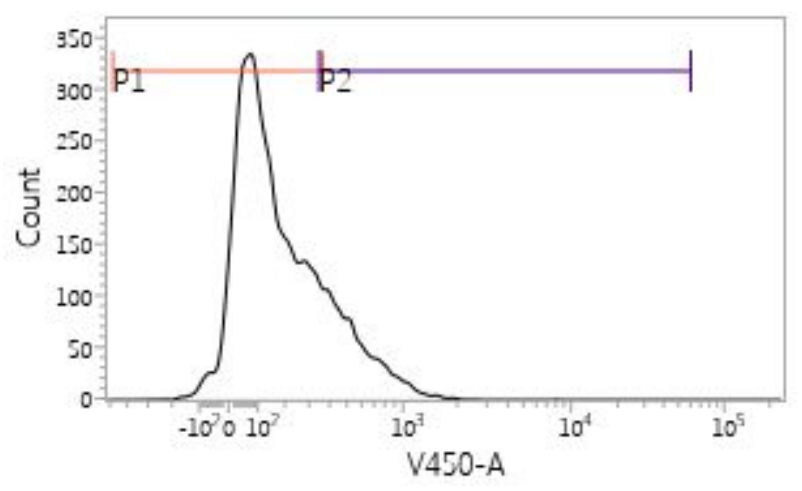

Control

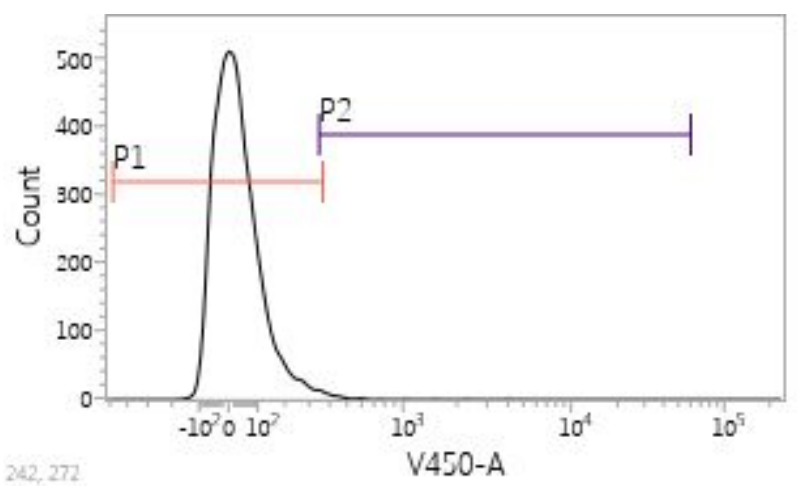

$0.70 \mathrm{nM}$

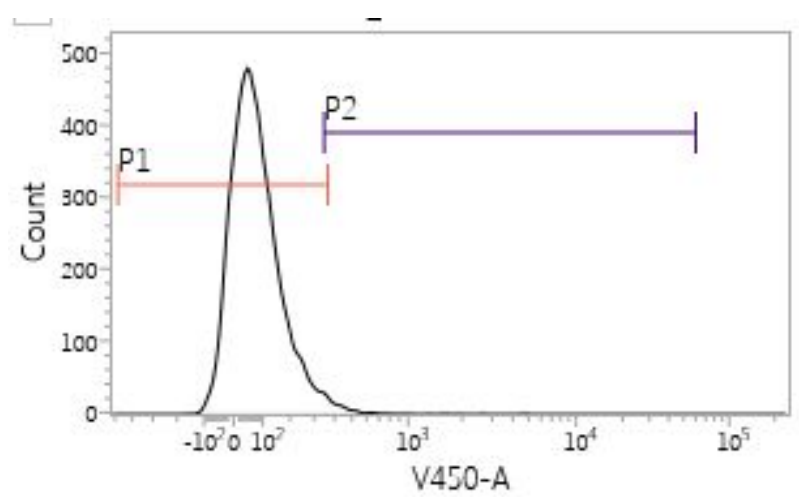

$0.35 \mathrm{nM}$

\begin{tabular}{|l|l|l|l|l|l|}
\hline Name & Events & \% Parent & \% Grandparent & \% Total & V450-A Mean \\
\hline Control:P1 & 7,939 & 79.39 & $* * *$ & 79.39 & 135 \\
\hline Control:P2 & 2,146 & 21.46 & $* * *$ & 21.46 & 611 \\
\hline $0.35 \mathrm{nM}: \mathrm{P} 1$ & 9,823 & 98.23 & $* * *$ & 98.23 & 85 \\
\hline $0.35 \mathrm{nM}: \mathrm{P} 2$ & 208 & 2.08 & $* * *$ & 2.08 & 535 \\
\hline $0.70 \mathrm{nM}: \mathrm{P} 1$ & 9,913 & 99.13 & $* * *$ & 99.13 & 39 \\
\hline $0.70 \mathrm{nM}: \mathrm{P} 2$ & 102 & 1.02 & $* * *$ & 1.02 & 517 \\
\hline
\end{tabular}

Figure S9. The statistics for the flow cytometric analysis of DNA fragmentation of VcN16961 (control and VL-AuNPs-treated, at two different concentrations), using DAPI dye. 


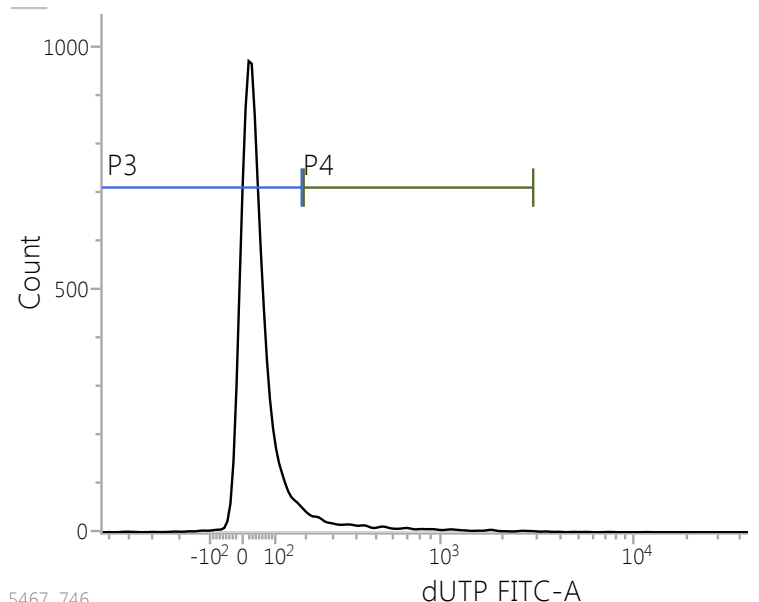

Control

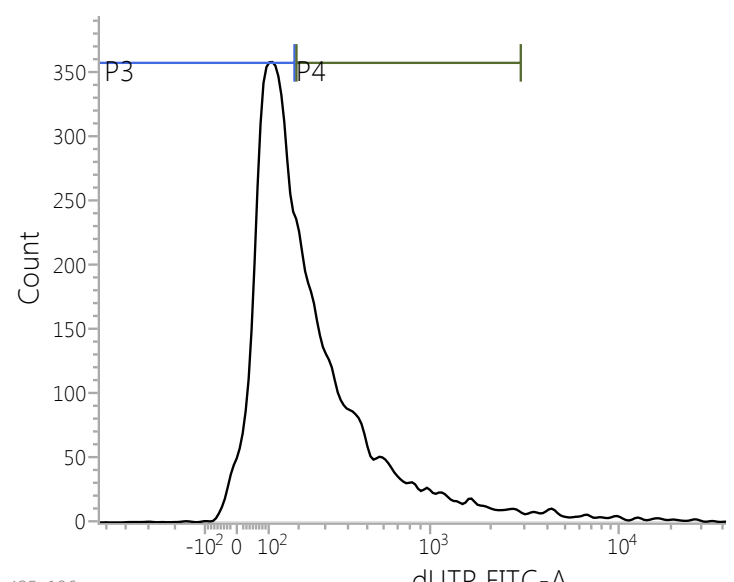

$0.70 \mathrm{nM}$

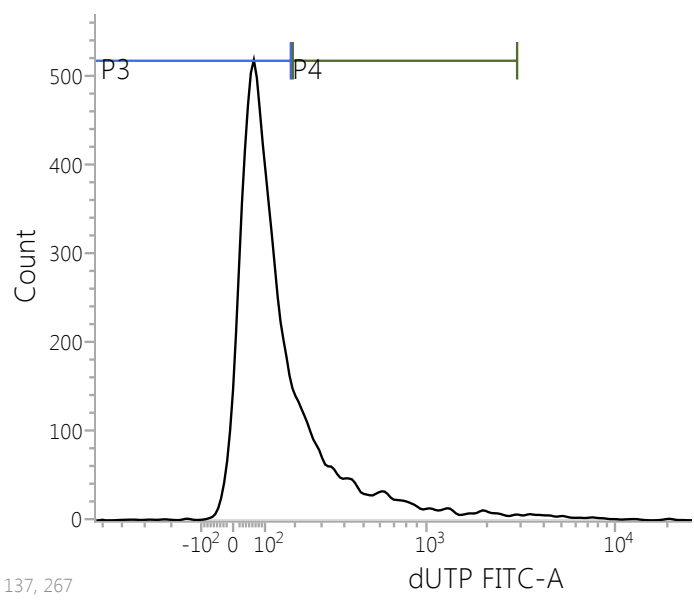

$0.35 \mathrm{nM}$

\begin{tabular}{|l|l|l|l|l|l|}
\hline Name & Events & $\%$ Parent & $\%$ Grandparent & $\%$ Total & dUTP FITC-A Mean \\
\hline Control:P3 & 9,158 & 91.58 & $* * *$ & 91.58 & 45 \\
\hline Control:P4 & 782 & 7.82 & $* * *$ & 7.82 & 575 \\
\hline $0.35 \mathrm{nM}: \mathrm{P3}$ & 7,075 & 70.75 & $* * *$ & 70.75 & 83 \\
\hline $0.35 \mathrm{nM}: \mathrm{P4}$ & 2,664 & 26.64 & $* * *$ & 26.64 & 526 \\
\hline $0.70 \mathrm{nM}: \mathrm{P3}$ & 5,005 & 50.05 & $* * *$ & 50.05 & 109 \\
\hline $0.70 \mathrm{nM}: \mathrm{P4}$ & 4,549 & 45.49 & $* * *$ & 45.49 & 519 \\
\hline
\end{tabular}

Figure S10. The statistics for the flow cytometric analysis of DNA fragmentation of VcN16961 (control and VL-AuNPs-treated, at two different concentrations), using TUNEL assay. 